\title{
What is it Happening in Reading Assessment?
}

\author{
Jo Fletcher, Karen Nicholas \\ University of Canterbury
}

\begin{abstract}
This paper explores how reading assessment is used to support 11- to 13-year-old students in reading. Learning to be an effective reader of a wide range of texts is critical for students as they reach young adolescence. Using a socially constructed ontology, a qualitative approach was used to explore the perceptions of five principals, seven teachers and nine parents. The five case study schools were situated in low to middle socio-economic areas in New Zealand. The study found that there was a range of methods of assessing reading and analyzing the data, and the analyses of data supported decisions school-wide in supporting low progress readers. Also, students were assessed against the National Standards and this information was shared with parents.
\end{abstract}

\section{Introduction}

Learning to be an effective reader of a wide range of texts is critical for students as they reach young adolescence. However, a significant proportion of young adolescents are performing below and well below benchmark levels in standardised reading assessments [1-3]. A downward trend in reading outcomes and motivation to read, often referred to as a slump or tapering off in students' progress in reading achievement, is apparent when students reach their middle years of schooling. Learning to read and continuing to sustain that growth are influenced by a complex range of factors. One key factor is the implementation of reading assessment and ways diagnostic analyses of these data can be used to give focused synergies towards making a difference in reading achievement.

Analyses of data from assessment in reading have multiple positive purposes. Variation in systems of assessment can work together in synergistic ways to inform teachers, school leadership teams, parents, governing bodies of schools, ministries of education and government policy makers by providing actionable evidence to enhance quality education [4]. Although standardised testing in reading can provide a macro environmental view of reading performance nationally, it can also be used within a school to drill down and find the explicit teaching that will further enhance a student's reading. Analysis of reading assessment data within a class, offers teachers instructionally relevant targeted feedback to develop explicit teaching strategies to raise outcomes of individual students. School-wide collation of these data analyses allows school leaders and governing bodies of schools to set up strategic targeting for reading support within the school. Furthermore, it provides principals with critical information to make decisions on allocation of resourcing.

When there is an understanding of how assessment data can inform decisions to improve outcomes in reading for all learners, teachers and principals can collaboratively develop school-wide strategies to improve reading. Knowledge of differing and new assessment instruments, raising teachers' understandings of the importance of diagnostic assessment practices, providing professional development in effectively interrogating data, and developing the capacity to target struggling readers can work together in making a difference in the next steps planning to raise achievement [5]. The OECD Review on Evaluation and Assessment Frameworks for Improving School Outcomes [6], outlined a holistic approach to assessment of learning [5] which supports Dempster and colleagues') findings. These include drawing on a variety of different types of assessment to gain a balanced view of the learner; using formative assessment processes; making sure that there is consistency in assessment across the school; using assessment formats that encompass key competencies; having assessment approaches that fit with particular education sectors, making use of ICT to support assessment and ensuring that assessment is inclusive and responds to the needs of the wide range of learners [6].

This research article explores views on what is happening in reading assessment for young adolescent students in New Zealand schools. Using a multiple site case study research approach, the perceptions of 21 stakeholders comprising seven teachers, five principals, and nine parents of 11 to 12-year-old students from five case study schools in low to middle socioeconomic areas were investigated. We wanted to find out how the assessment of reading informs principals, teachers and parents to support higher achievement in reading for 11 to 13-year-old students in New Zealand schools. 


\section{Literature Review}

In New Zealand, and internationally, reading underachievement persists. For example, the 2011 Progress in International Reading Literacy Study (PIRLS) of 10 year-old students' reading achievement highlighted that, in countries such as New Zealand, Australia and England, although students are achieving at high levels in reading, there remain significant percentages of students who are underachieving [3], [7]. In New Zealand, 25 percent of students were below the 'Low International Benchmark' or at the 'Low International Benchmark' in reading. This was similar to Australia, with 24 percent of students below or at the 'Low International Benchmark', whilst England was better with 17 percent, and both Canada and the United States had 14 percent of students below or at the 'Low International Benchmark' [3, 8]. These percentages of students reading at low levels comprise a significant proportion of the school population, particularly in New Zealand and Australia.

\subsection{Use of data to inform performativity}

O'Brien, Stewart and Beach [9] contend that the use of data from large scale standardised assessments have the potential to operate from a narrower base of what reading proficiency is and can discourage diversity in learning. Furthermore, large scale standardised measurements of reading outcomes often have been used to offer accountability and bolster public perceptions of schooling [10]. Hardy [11], when discussing the standardized measures of students' learning outcomes within a school, problematizes the competing tensions for a principal between using appropriate assessment data to improve outcomes and presenting the public face of being a successful school. In times of reform in education, kudos is frequently given to high performing schools, where principals maximise the achievement outcomes using standardized measures and standards. However, this can narrow the focus of schooling to measurable goals of attainment in set curriculum, such as reading [9], [10].

In recent years, the performativity of students in areas such as reading and writing has been frequently measured in a more accountable manner, with benchmark standards and testing becoming an intrinsic part of schooling. For example, in New Zealand, National Standards in reading, writing and mathematics were introduced to inform students and parents of individual attainment. The decision on the best fit category for a student to be benchmarked at, is determined by an overall teacher judgement that draws on the analyses of a range of assessment data, rather than on one standardised test result. The four categories are 'Well below', 'Below', 'At' and 'Above' National Standards at the specific year level of schooling. Additionally, school principals are required to report to the Ministry of Education specific data on overall student achievement at year levels, and by gender and ethnicity. This type of performative pressure in New Zealand, also confronts school leaders around the world in an era of accountability measures [9]. If the performance of teachers is deemed to be measured in raising achievement using standardised test results alone, then teachers and their leadership team may opt to focus on teaching for the test [12].

The sole use of national standards as indicators of effective teaching and schooling can be problematic. Martin et al. [13] suggest that effective forms of pedagogical interventions and strategies are those which require students to engage in 'high order thinking', 'deep understanding' and 'personal constructions of knowledge'. Such approaches offer students understanding and cognisance that will support their lifetime endeavours. For example, when teachers provide a learning environment where young adolescents discuss texts, and have the opportunity to talk with their peers and teachers for extensive periods of time, then during the discourse students can critically analyse and debate meanings within texts. Pedagogical approaches to learning that foster proactive inquiry permit students to develop confidence and be critically responsive citizens [13].

Quantifying this type of understanding can be problematic. Performative demands on school leaders often use the criterion for excellence, as significant achievement increases in standardised test results. These types of measures can obscure qualitative facets of achievement. Quantitative measurements of learning using testing provide a narrower understanding of the wider goals of education [12].

\subsection{Cultural considerations}

Eurocentric pedagogical approaches and resources utilised by many teachers, assessment measures cannot be considered devoid of culture. Klenowski [10] contends that culture-free assessment does not exist. This can disadvantage minority ethnic cultures. For example, in the Australian education systems Indigenous Aborigine students continue to be labelled as failing. In the 2012 Programme for International Student Assessment (PISA) in reading literacy, the Australian Indigenous students recorded a mean score of 428 points, in comparison to a mean score of 515 points for nonIndigenous students. The difference of 87 score points equates to two-and-a-half years of schooling [3]. This situation of Indigenous and minority ethnic students underachieving in reading, especially those from low socioeconomic backgrounds aligns with 
the New Zealand context. In the 2011 Progress in International Reading Literacy Study (PIRLS), underachievers in New Zealand were more highly represented by students from some diverse cultural backgrounds [7]. Māori students (the indigenous people of New Zealand) and Pasifika students (a term used in New Zealand to encompass students deriving from the wide range of Pacific Islands, such as Tonga, Samoa and Solomon Islands) scored below the mean international PIRLS Scale Centrepoint of 500, with Māori at 488 and Pasifika at 473. Significantly higher, was the New Zealand/European mean score of 558 and the Asian mean score of 542 [7].

The 2013 OECD Review on Evaluation and Assessment Frameworks for Improving School Outcomes [6] which examined the assessment policies in 28 countries advocates placing the learner at the centre. Central to a child is their family and their understandings about their child's progress in schooling. One of the synergies for effective learning is communication and sharing of outcomes with the students and their parents. This can be achieved by engaging parents in the progress of their children through effective reporting and opportunities to communicate with the teacher, alongside allowing students to engage in the assessment of their learning. The inter-relationships amongst the school principal and the teacher, parents and the school staff are critical to a student's reading development. These key stakeholders, such as parents, teachers and students, need to be considered and included when addressing the needs of literacy learners, particularly those of marginalised students. Effective home school partnerships and parents' involvement in their child's education are critical. This has been highlighted by Hattie [14], who in his syntheses of over 800 meta-analyses that relate to student achievement, found the impact of parental involvement in students' academic achievement had a notable effect size (.51). If parents are to be part of the network of support for children' reading, then ensuring they have sound understandings of the types of assessment strategies, both formative and summative, and how these can be used to plan next steps teaching and learning are key.

\subsection{Theoretical perspective on reading}

Reading acquisition from a social constructivist perspective is that it is shaped through interactions with others. The theoretical writings of Vygotsky [15] are fundamental to such theoretical perspectives, especially the zone of proximal development where teaching by colleagues and teachers is vital to extend new knowledge. In progressing these theoretical perspectives, Ruddell and Unrau [16] view reading acquisition from a sociocognitive perspective and discuss how reading should be conceptualised as a meaning-construction and meaning-negotiation process. Families and the wider community can influence the sociocultural values and attitudes of the reader. Aligning with socio-cultural and social constructivist perspectives, when students' particular cultures and family experiences are compatible with the culture of their schools and their teachers, it is more probable that they will flourish in their learning and motivation to succeed [17]. In addition, student motivation can be further enhanced by providing culturally congruent texts.

\section{Methodology}

A qualitative paradigm was used to explore what was happening in the assessment of reading for 11 to 13-year-old students (Years 7 and 8) in five New Zealand case study schools. In New Zealand, students commence secondary schooling in Year 9, from approximately 13 years of age. Multiple case studies were explored to address the question: 'How does the assessment of reading inform principals, teachers and parents to support higher achievement in reading for 11 to 13 -year-old students in New Zealand schools?' By looking from different vantage points of the principals, teachers and parents we sought to gain a critical awareness in our interpretations and analyses of the evidence. In our research, a total of 21 participants were individually interviewed using a semi-structured interview schedule. Questions were used as a guide to shape the interview but did not constrain discussions to a predetermined agenda. The types of questions for the teachers and principals included: What Year 7 and 8 assessment practices in reading are used in your class and how are the data used to inform teaching of your students? What do you put in place for your low progress Year 7 and 8 readers? What support in reading achievement do you have in place for your culturally diverse students? For the parents, the types of questions included: How do you know how well your child is doing in reading at school? What concerns you most about your child's reading and what assistance, if any, have you sought? The individual interviews were approximately 40 to 50 minutes in length, were audiotaped and later transcribed.

\subsection{The schools and the participants}

Two of the schools were situated in very low socio-economic areas and three were in low to middle socio-economic areas. The sizes of the school rolls ranged from 110 to 426 . Four schools were state schools and one was a state integrated school. Usually integrated schools are schools with a special character, such as Roman Catholic. The ethnicity of New Zealand European in Schools Four, One, Three and Five were 40 percent, 46 percent, 52 percent and 
61 percent respectively, whilst at School Two it was 85 percent. The other two main ethnic groups were Māori and Pasifika, with Māori ranging from14 percent to 28 percent, and Pasifika ranging from 0 percent to 25 percent of a school's student population. The participants included seven teachers, five principals, and nine parents of 11 to 13 -year-old students.

\subsection{Data analysis}

To commence the analysis of data, emerging themes were identified. These provided a guide to separate the data into early coding categories. In the next phase, the interview transcripts were re-read. Axial coding was used to break the data open and find connections between categories and sub categories. For example, the parents' discussion about reporting of their children's reading achievement linked to the emphasis in New Zealand on National Standards and what level their child was judged to be performing at in reading. The concluding stage used selective coding to look over the data. During this process of selective coding, the major concepts or codes that reappeared frequently guided the research. The focus was to identify the higher order predominant concepts and categorise them more precisely. The themes included methods of assessing and analysing in the school, assessments' role in supporting low progress readers, National Standards and communication with parents on reading achievement.

\section{Findings and discussion}

\subsection{Methods of assessing and analysing in the school}

In New Zealand, school leaders are able to select which types of tests they prefer to use. In our case study schools, the teachers and principals reported that they used evidence from standardised testing undertaken usually once or twice a year. This evidence took the form of the students' scores from some of the standardised tests of reading achievement commonly used in New Zealand primary schools: the Assessment Tools for Teaching Learning (asTTle) [18], including the online version e-asTTle, or the Supplementary Tests of Achievement in Reading (STAR) [19] or the Progressive Achievement Tests (PAT) in reading comprehension and listening comprehension [20] (STAR is a norm-referenced, New Zealand contextualised assessment tool that measures a range of reading skills (word recognition, sentence and paragraph comprehension, vocabulary knowledge, advertising language and writing style). For example, at School One, the principal and a teacher explained:
So the types of testing that we do down at the senior end of the school are looking at asTTle Reading, and STAR. We try and stay within the standardized tests so that we have a wee bit more direction in terms of where the kids are at. (Principal, School 1)

We do STAR and asTTle reading. We do some paper [asTTle] and some $e$ asTTle [online] because we don't have enough computers to do them all at once. Also, because we have three [year] levels in there so when we do the testing, it becomes a bit of a nightmare. Running Records, we take with kids below Stanine 4. We do PAT listening and PAT comprehension as well. (Teacher, School 1)

STAR testing allocates a student's reading achievement according to stanines. With STAR, a stanine score of 1 to 3 is below average, 4,5 and 6 is average, 7 and 8 are above average, and 9 is outstanding. One possible problem with STAR, is that for students who are high achievers in reading, there is a ceiling effect which means it does not show growth in reading achievement. However, for students who are at the middle and lower levels of reading achievement, it is a useful tool for diagnosing next steps learning. At School One, similar to other schools, those students who scored at a lower stanine are tested using Running Records. This one-on-one assessment allows for a formative analysis of reading strategies used to decode words and read for meaning. Similar to School One, the teacher at School Four said:

We have our assessment school-wide.

We do STAR, asTTLe, and Running Records on any students below National Standards. This year I did Running Records on 15 of my students. We do that in Term 2 and 4. (Teacher A, School 4)

Although e-asTTle, an online version of asTTle, has been developed, one teacher outlined the difficulties children had using online testing. We do the asTTle reading test twice a year... but not online [e-asTTle]. We started doing it online, but found they were really struggling because they didn't have the skills and also they were doing it on tiny little netbooks and with the split screen. It is really hard. They were not doing as well as we thought they could do. So when we went back to paper, they did better. So now we are doing it on paper even though it means we have to put it all into the computer. We manually put it 
in. We also put it into our reading programme for doing some multichoice questions and referring back to the text and highlighting key things. That is study skills as well as testtaking skills. It never occurred to me that they didn't know they could refer back to the text. Some of them just seem to think that you read it and just have to answer the questions from memory. Maybe because that is what you have to do with a running record. The really good readers were okay. It didn't make any difference whether they did it online or not. The poor readers it didn't make any difference because they were not reading very well anyway. But the ones in the middle did much better on paper than on a computer. (Teacher B, School 4)

Careful analysis of the wider issues around the logistics of the manner in which a test is administered, allowed the teachers to overcome barriers to indicating the actual reading achievement of students. This highlights how some types of reading assessments may not be assessing what is intended, and how individual results can be marred by wider logistical issues.

\subsection{Supporting low progress readers}

The results from the standardised testing were used to identify students who were achieving at low levels in reading acquisition. This usually involved some form of collaborative interrogating of the assessment data with other colleagues. Similar to Dempster et al.'s [5] findings in the principals as literacy leaders' research in Australia, the principals' engagement and knowledge of data analysis in our case study schools enhanced the capacity schoolwide to improve literacy learning.

At a class level, we have an interview with the teacher where we go through the results and ask them to comment on the progress and what they are doing to cater for each group of children in their class. We go through with their results and we ask how they are going and what their needs are and what the teacher is doing in response to that. (Principal, School 4)

In a similar manner, the principal of School One explained how he and his teachers collaboratively interrogated the assessment data.

We crunch it all up and we spit it all out at a staff meeting. We have all the achievement information out on the tables in the staff meeting and the staff have to walk around and look at four key factors - What does the data show us? What are the strengths and weaknesses of the data? Are there any trends that you can see? What are our next steps? From that information the teachers actually get their selfmonitored teaching as inquiry selfmonitored students groups, and they extract four or five kids that they want to move in Literacy and Numeracy and they put in place a plan around that. First of all, they try and chunk what they are doing in the class environment and then they look at what they need to change to meet the needs of those learners. So they might be ESOL [English Speakers of Other Languages] kids, as an example, who they have identified as target learners. What does the base line data show you and evaluate the strategies that they are trying to change? (Principal, School 1)

This targeting of at-risk learners indicated a systemic school approach to children's literacy learning and achievement. For one school, the cluster schools in his area had been involved in ongoing professional development in raising outcomes in reading and the strategies outlined and discussed during these meetings informed their current practices.

We have operated target groups as well, so we are monitoring those students. That comes back from our days working with our cluster schools. We are targeting small groups and monitoring those and talking about them within the teams quite regularly. We have a pretty good indication of where they are and how they are going. (Principal, School 2)

The professional development at School Two aligns with Dempster et al. [5] who advocate for professional development to target struggling readers. Of the five case study schools, School Two was the only school which had been involved in recent professional development in literacy.

At School Five, they had employed a remedial reading teacher to work on an individual basis with low progress readers.

They do asTTle assessment at the beginning of the year and at the end of the year. Those who are quite low can go and be assessed by the lady that does remedial reading and she will do a Running Record on them and see right 
where they are at, and say, "Yes, I think I need to work with them". They will go away with her for however long she thinks is necessary. So I may not see them all year. I may see them back halfway through the year because they have caught back up to where they need to be. Those who don't go down to her stay with me and I group them based on their ability. (Teacher, School 5)

Although the practice at this school was to send low progress readers to a remedial reading teacher, the other schools in our study preferred that the classroom teacher worked alongside these most atrisk students.

\subsection{National Standards}

In New Zealand, National Standards in Reading are based on an overall teacher judgement using a range of assessment measures. This practice aligns with the recommendations of the OECD review on assessment frameworks to improve school outcomes where they suggest teachers draw on a variety of different assessments to gain a balanced view of the student's learning and achievement. The principal of School One explained how his staff used the analysis of the reading assessment data to decide on National Standards levels.

We use a variety of data. We test
twice a year... It is based around the
best evidence synthesis process in our
Area Cluster model [cluster of
neighbouring schools that work
collaboratively] that we had at our
school, where they articulated that the
best testing times were the end of
Term 1 and the end of Term 3 . It gives
you plenty of time to digest the
information and convert it into the
National Standards, through quite a
lengthy process of course. (Principal,
School 1)

At School Two, a teacher described how he used anecdotal observation notes and the standardised test results to base his overall teacher judgement on what National Standard level each child was achieving at in reading.

We are using asTTle and STAR, but don't use PAT reading. I am a big one on the bookwork and always marking their work and having comments and once I have written a comment, they will write something back. We are constantly doing that. It is a teacher judgement thing. When I have a reading group with me, I will scribble my notes on my timetable and keep a track of it that way. That is really it, their bookwork, the discussions I observe and the standardised tests. (Teacher B, School 2)

At School Three, a very multicultural school, the principal explained how the teachers were cognisant of individual student's ethnicity and home backgrounds and were endeavouring to provide a learning culture that aligned with the students' differing backgrounds [17]. At this school, the principal indicated that Māori students were performing at both ends of the reading achievement continuum.

I would be looking at the child that is below National Standards. It is really important to keep all the student's own potentials going. That is why we do the Hauora [Mãori term for wellbeing and motivation to learn] survey so we know what is going on. Then we would use those other backgrounds [cultural and home] that we have. We do not pull them out as a group [NonEuropean students]. We are finding here that our Māori students are actually at both ends. They are in the 'Above' and in the 'Below' National Standards levels. They are not a group that stands out as a tail... But we are aware of the cultural backgrounds. The school is small enough that all the teachers know [students' backgrounds and ethnicity]. (Principal, School 3)

The use of the well-being and motivation survey provided another lens to assess the students. This aligns with sociocultural activity theory perspective that suggests students who have some internal motivation are more likely to succeed [9].

The requirement to assess students to National Standards and provide the overall results to the Ministry of Education as a measure of the effectiveness of teacher and student performance was not viewed positively by one principal. At his small, low socio-economic multicultural school, the recent arrival of a cohort of Samoan students, with English as a second language, had meant that this had pulled down the year level performance in reading.

I am not the biggest fan [of National Standards] on the planet to be honest. The National Standards don't tell the story of what is lying behind the data. Our National Standards are quite low at the moment and that is only because we have $75 \%$ or 9 out of 12 of our learners at the Year 6-8 level who have just recently come to our school 
are Samoan. They have come straight 'off the boat' with little language. There are lots of stories behind every poor result. There were 12 learners below in the National Standards. Out of those 12 [students], nine were from Samoa. Our interim results are quite distorted because of that fact. (Principal, School 1)

Arguably, students who are learning the English language, and have only recently arrived in a country should be placed in an alternative category in regards to reporting levels in National Standards.

\subsection{Informing parents about student progress in reading}

In New Zealand, the parents at a school elect nominated parents to the school's governing body, called the Board of Trustees. The Board of Trustees, which includes the principal and a teacher delegate, is responsible for setting the strategic direction of the school with a particular focus on raising student achievement. The principal at School Four explained how the standardised test results were shared with the Board of Trustees.

The standardized tools that we use are asTTle reading and STAR. As a principal we obviously use the data to report to the Board of Trustees on progress over time, and cohort the children that are achieving and not achieving. (Principal, School 4)

The principals at the five case study schools promoted strong connections with parents. Individual parent interviews with the child's teacher were common practice at all of the case study schools. This provided an opportunity for the parents to find out how well their child was achieving in reading.

At reporting time, the asTTle results for reading and maths are put in front of parents and it is explained to them. We give it to them in simple language. (Principal, School 5)

Attendance of parents at school interviews is important. At School four, a strategy to encourage children to get their parents to attend interviews had been successful.

On the whole, they are pretty good at coming to parent interviews actually. The Pasifika families value education and in many cases they came here to get their kids a better education. Although they don't always know, because their educational background is very different, so they don't always know what they need to do at home, but they are really good at coming to interviews... We started a competition where the class which got the highest amount of interviews attended, they won a prize. If you got over 80 percent [parent attendance], you got ice-creams. That really improved the attendance. (Teacher B, School 4)

The parents confirmed that parent interviews provided an opportunity to be informed of their child's progress across the curriculum and in reading achievement. Two parents said:

We have had one interview with the teacher and another one is coming up. Reports that we get each term. The school always encourages the parents to make contact with them if we have any concerns. (Parent C, School 3) We had a learning interview about two weeks ago, and she showed me on the graph where he was in terms of the National Standards. (Parent A, School 4)

One parent, whose daughter was reading at a low level, discussed how she wanted to know the level of achievement in reading.

We had a parent interview meeting and she was below the National Standard in everything I think. It wasn't that long ago. I think it was the beginning of June. It wasn't a shock. She has always been below the National Standards. She has been there forever, so it wasn't really a shock. Well, I think it is best to know. I'd sooner know. (Parent, School 1)

While the parent discussed this with the interviewers she became visibly upset. Finding out that your child is a struggling reader allows a parent to be aware of the situation. Nevertheless, it would make for good practice if teachers, when informing parents that their child is performing at a low level in reading, to also offer some positive strategies that they and the parent/s can implement to help improve reading outcomes.

\section{Conclusions}

Assessment practices in reading at the five case study schools were widely implemented to inform teachers of the progress of each student in reading. All of the schools used standardised testing in reading during the school year. The school staff selected from a range of standardised tests commonly used in New Zealand and worked collaboratively to interrogate the data. Some of the principals reported that they were actively engaged in the analyses of the reading data. Clearly, these principals recognised that leadership involved focusing attention on the centre-piece of their profession, the achievement and learning of the 
students [5]. Data from a range of reading assessments allowed for an overall teacher judgement on the National Standards reading level for their year of schooling. This concurred with the OECD review on evaluation and assessment which recommended drawing on a variety of assessment types to gain a balanced view of the students' achievement.

The information from the standardised test results gave focused information, identifying target groups of students needing further support in reading. Frequently, the low progress students identified were then tested using a Running Record which allowed an opportunity to analyse the strategies the student was using to decode words and seek meaning from the text. This allowed for explicit teaching to specific needs of individual learners. One principal of a small multicultural school expressed concerns about the use of National Standards as the overall results school-wide may not tell what lies behind the data. At the 7 to 8-year level of the school, the recent arrival of a sizeable group of Pasifika students, who were in the initial stages of learning English as a second language, had pulled the overall National Standards levels down. The National Standards results by year level can be visible to the general public online. As Hardy [11] problematizes when discussing the public reporting of school-wide assessment results, the public face of the school can be presented negatively, without any background explanation to underlying circumstances that have impacted on the results.

Home-school partnerships during the parent teacher interviews were fostered, and the discussion of each child's specific skills and motivation in reading provided a nexus for the parents and the teachers. During interviews, the teachers reported the child's reading assessment achievement results, including National Standards levels. Parents should be made aware of the assessment results for their child. When a teacher is reporting that a child is 'below' or 'well below' the National Standards, a teacher's cognisance and sensitivity to the possible emotive situation that might arise from this information is critical. Supporting this information with positive strategies to improve reading outcomes is essential.

What appeared to be missing from the analyses of data from four of the five case study schools was evidence of professional development in interrogating assessment data in reading, and how that data can be used for explicit teaching to raise reading outcomes. We align with Dempster et al. [5], and call for opportunities to raise teachers' understandings of the importance of diagnostic assessment practices. By providing professional development to effectively interrogate data and develop the capacity to target struggling readers, a teacher makes a difference through next steps planning to raise reading achievement.

\section{References}

[1] Chamberlain, M. PIRLS 2010/11 in New Zealand: An overview of national findings from the third cycles of the Progress in International Reading Literacy Study (PIRLS). 2014; http://www.educationcounts.govt.nz. (Accessed: March 21, 2016).

[2] Twist, L., et al., PIRLS 2011: Reading Achievement in England: Executive Summary. 2012: Slough, Berkshire.

[3] Thomson, S., et al., Highlights from TIMSS \& PIRLS 2011 from Australia's perspective. 2012, ACER: Australia.

[4] Gordon Commission, A public policy statement: The Gordon Commission on the futureof assesment in education. 2013.

[5] Dempster, N., et al., Principals as literacy leaders; Confident, credible and connected. 2012, Australian Primary Principals Association: Kingson, ACT.

[6] OECD, 'Synergies for Better Learning: An International Perspective on Evaluation and Assessment, Pointers for Policy Development'. 2013.

[7] Chamberlain, M., Reading Literacy: A summary of findings for New Zealand from the third cycle of the Progress in International Reading Literacy Study (PIRLS) 2010/11. 2013, Comparative Education Research Unit, New Zeland Ministry of Education: Wellington.

[8] Labrecque, M., et al., PIRLS 2011 Canada in Context. 2012, Council of Ministers of Education Canada: Toronto, Ontario.

[9] O'Brien, D., R. Stewart, and R. Beach, Proficient reading in school: Traditional paradigms and new textual landscapes, in Handbook of adolescent literacy research, L. Christenbury, R. Bomer, and P. Smagorinsky, Editors. 2009, Guilford: New York. p. 80 - 97.

[10] Klenowski, V., "Towards fairer assessment". Australian Educational Researcher, 2014. 41: p. 445-470.

[11] Hardy, I.J., "Leading learning: theorizing princials' support for teacher PD in Ontario". International Journal of Leadership in Education: Theory and Practice, 2010. 13(4): p. 421- 436.

[12] Gorard, S., "Serious doubts about school effectiveness". British Educational Research Journal, 2010. 36(5): p. 745-766.

[13] Martin, J.R., P. Freebody, and K. Maton, "Talk, text, and knowledge in culmative, integrated learning: a response to 'intellectual challenge'." Australian Journal of Language and Literacy, 2008. 31(2): p. 188-202.

[14] Hattie, J., "Visible learning: a synthesis of over 800 meta-analyses relating to Achievement". 2009, London: Routledge. 
[15] Vygotsky, L.S., "Mind in society: The development of higher psychological processes". 1978, Cambridge, MA: Harvard University Press.

[16] Ruddell, R. and N. Unrau, "Reading as a meaningconstruction process: the reader, the text, and the teacher", in Theoretical models and processes of reading, R. Ruddell and N. Unrau, Editors. 2004, International Reading Association: Newark, DE. p. 1462-1521.

[17] Macfarlane, A., "Motivating Maori students in literacy learning: Listening to culture", in Motivating literacy learners in today's world, J. Fletcher, F. Parkhill, and G. Gillon, Editors. 2010, NZCER: Wellington. p. 8998.

[18] Ministry of Education, AsTTle: Assessment Tools for Teaching and Learning, Version 3. 2003, Auckland: University of Auckland.

[19] Elley, W.B., STAR Supplementary Tests of Achievement in Reading Years 4-9. 2001, New Zealand Council for Educational Research: Wellington.

[20] NZCER. Progressive Achievement Tests (PATs). 2016; http://www.nzcer.org.nz/tests/pats (Accessed: March 23, 2016). 